\title{
Correction: Expanded HTA: Enhancing Fairness and Legitimacy
}

\author{
Norman Daniels ${ }^{*}$, Thalia Porteny ${ }^{2}$, Julian Urrutia ${ }^{2}$ \\ Received: 28 March 2016, Accepted: 2 April 2016, ePublished: 3 April 2016
}

The authors would like to correct the name of the third author in this paper to Julian Urrutia.

The original article was published in Int J Health Policy Manag. 2016;5(1):1-3. doi:10.15171/ijhpm.2015.187.

Copyright: (c) 2016 by Kerman University of Medical Sciences

Citation: Daniels N, Porteny T, Urrutia J [correction of Urritia J]. Expanded HTA: enhancing fairness and legitimacy [published correction appears in Int J Health Policy Manag. 2016;5(5):347]. Int J Health Policy Manag. 2016;5(1):1-3. doi:10.15171/ijhpm.2015.187 